\title{
Genetic and expression analysis of the KCNRG gene in hepatocellular carcinomas
}

\author{
Yong Gu Cho', Chang Jae Kim", \\ Jae Hwi Song ${ }^{1}$, Duck Joo Rhie ${ }^{2}$, \\ Yong Kyu Park ${ }^{3}$, Su Young Kim ${ }^{1}$, \\ Suk Woo Nam ${ }^{1}$, Nam Jin Yoo', \\ Jung Young Lee ${ }^{1}$ and Won Sang Park ${ }^{1,4}$ \\ ${ }^{1}$ Department of Pathology \\ 2Department of Physiology \\ ${ }^{3}$ Department of Statistics \\ College of Medicine \\ The Catholic University of Korea \\ Seoul 137-701, Korea \\ ${ }^{4}$ Corresponding author: Tel, 82-2-590-1190; \\ Fax, 82-2-537-6586; E-mail, wonsang@catholic.ac.kr \\ Accepted 20 May 2006
}

Abbreviations: HCC, hepatocellular carcinoma; KCNRG, potassium channel regulating gene; MTS, 3-(4,5-dimethylthiazol-2-yl)-5-(3carboxymethoxyphenyl)-2-(4-sulfophen-yl)-2H-tetrazolium; SSCP, single-strand conformation polymorphism

\begin{abstract}
The potassium channels are ubiquitous multisubunit membrane proteins, and potassium-dependent alterations in the membrane potential play an important role in the proliferation of many types of cells. This study analyzed the mutation, allelic loss and expression patterns of the KCNRG gene in 77 HCCs in order to determine if the KCNRG gene, which encodes the potassium channel regulating protein, is involved in the tumorigenesis of hepatocellular carcinoma (HCC). One KCNRG missense mutation, CGT $\rightarrow$ CAT (Arg $\rightarrow$ His) was found at codon 92 within the T1 domain. Hep3B hepatoma cells were transfected with the wildor mutant-KCNRG to determine the effect of this mutation in KCNRG. Interestingly, the suppressive cell growth activity of the mutant-type KCNRG was significantly lower than that of the wild-type KCNRG. In addition, allelic loss was detected in 17 out of $64(26.5 \%)$ informative HCC cases, and all were hepatitis B virus (HBV)-positive. Moreover, the allelic loss was closely related to an intrahepatic metastasis $(P=0.0247)$, higher grade $(P=0.0078)$ and clinical stage $(P=0.0071)$. Expression analysis
\end{abstract}

revealed 22 tumor tissues to have a loss of expression of the KCNRG transcript. These results suggest that genetic alterations and the expression of KCNRG might play an important role in the development and/or progression of a subset of HCCs.

Keywords: carcinoma, hepatocellular; KCNRG protein, human; loss of heterozygosity; mutation, missense; potassium channels

\section{Introduction}

Hepatocellular carcinoma (HCC) is one of the most common cancers in the world, with the highest incidence being in Southeast Asia and Africa. In Korea, HCC accounts for approximately $12.2 \%$ of all malignancies, $16.4 \%$ in the male population and $6.5 \%$ in the female (Shin et al., 2004). Etiological studies have shown that an infection with the hepatitis B or C virus (HBV or HCV) and the ingestion of aflatoxin B1-contaminated food might be important risk factors for HCC (Chen et al., 1977). In addition, cirrhosis resulting from heavy alcohol consumption is a major risk factor in some westernworld countries. Generally, the majority of HCCs are associated with a background of chronic liver disease, such as cirrhosis and chronic active hepatitis, suggesting a multistep process in its development (Sakamoto et al., 1991). However, the genetic events involved in the carcinogenesis of $\mathrm{HCC}$ are unclear.

The development of human cancers results from the clonal expansion of genetically modified cells that acquire a selective growth advantage through accumulated alterations of proto-oncogenes and tumor suppressors (Kumar et al., 2003). The somatic inactivation of a tumor suppressor gene is usually caused by an intragenic mutation in one allele of the gene with the subsequent loss of a chromosome region that spans the second allele. Frequent chromosomal losses in carcinomas arising from certain epithelial cells suggest that the putative tumor suppressor gene(s) reside(s) on the affected chromosomal arm. Several cytogenetic studies reported that chromosome $13 \mathrm{q}$ is one of the common deletion regions and contains one or more of the genes associated with the development or progression of HCC (Niketeghad et al., 2001; Crawley et al., 2002; 
Kusano et al., 2002; Wong et al., 2002). Surprisingly, allelic losses at $13 q$ were found to be associated with an advanced tumor stage and a poor prognosis (Zondervan et al., 2000; Kusano et al., 2002; Wong et al., 2002). The potassium channels are ubiquitous multisubunit membrane proteins that regulate the membrane potential in several cell types, and potassium-dependent alterations in the membrane potential play a pivotal role in the proliferation of many types of normal and tumor cell lines. For example, the membrane potential in the early $\mathrm{G} 1$ phase is depolarized and the transition from the $\mathrm{G} 1$ phase to the $S$ phase during mitosis is accompanied by hyperpolarization of the membrane potential (Wonderline et al., 1995). In MCF-7 cells, this hyperpolarizing transition requires the activation of the ATP-sensitive $\mathrm{K}^{+}$and $\mathrm{Ca}^{2+}$-sensitive $\mathrm{K}^{+}$channels (Wonderline et al., 1995). Interestingly, drugs blocking these $\mathrm{K}^{+}$channels, such as quinine and glibenclamide, inhibit the growth of many types of cells, ranging from quiescent lymphocytes stimulated by mitogens to rapidly cycling tumor cells, and arrest the cell cycle (Woodfork et al., 1995; Wonderlin et al., 1996). Recently, Ivanov et al. identified a new tumor suppressor gene, the KCNRG gene, which encodes a potassium channel regulating protein and located in 13q14.3 (Ivanov et al., 2003). Therefore, the inactivation of the KCNRG through primary structural changes, such as mutations and allelic losses, might be involved in the development or progression of various human cancers, including HCC.

This study analyzed mutation, allelic loss and expression pattern of the KCNRG gene on a series of 77 Korean HCCs. In addition, an in vitro expression study was performed to determine their functional consequence of the KCNRG on cell proliferation and on potassium channel regulation.

\section{Materials and Methods}

\section{Tissue samples}

A total of 77 frozen HCC samples were examined. Informed consent was obtained from all patients. No patient had a family history. Their ages ranged from 26 to 89 years, with an average of 60 years. The male to female ratio was 63 to 14 . Three pathologists independently reviewed one $6 \mu \mathrm{m}$ section stained with Hematoxylin \& Eosin . The background liver showed cirrhosis in $53(70.1 \%)$, chronic active hepatitis in $9(11.7 \%)$, chronic persistent hepatitis in $3(3.9 \%)$, fatty changes in $1(1.3 \%)$, and nonspecific changes in $11(14.3 \%)$ cases.

\section{DNA and RNA extraction}

The frozen tissue samples were ground to a very fine powder in liquid nitrogen. The genomic DNA was prepared using a procedure described previously (Park et al., 2005). The total RNA was extracted using the Trizol reagent according to the manufacturer's protocol (Invitrogen, Carlsbad, CA).

\section{SSCP and DNA sequencing}

The genomic DNAs from each cancer cell and corresponding non-cancerous liver tissues were

Table 1. Primer sequence for amplifying the coding region of the KCNRG gene.

\begin{tabular}{|c|c|c|}
\hline Name of primer & Nucleotide sequences & Product size $(\mathrm{bp})$ \\
\hline Exon $1-1 \mathrm{~F}$ & 5'-GTAGCCTCTAGTTTGAAGTGAG-3' & \multirow{2}{*}{210} \\
\hline Exon $1-1 \mathrm{R}$ & 5'-ATGAAACTAAACAAATCACCAT-3' & \\
\hline Exon 1-2 F & 5'-GTTGGTGGCCAGATTTTTTGT-3' & \multirow{2}{*}{229} \\
\hline Exon $1-2 \mathrm{R}$ & 5'-CTTGAGTGTTCCGGCTTAGG-3' & \\
\hline Exon $1-3 \mathrm{~F}$ & 5'-CCATACCTGCTACAGCCAAGA-3' & \multirow{2}{*}{209} \\
\hline Exon 1-3R & 5'-TGTGGAGGCAGTGGAAGTAAG-3' & \\
\hline Exon 1-4F & 5'-GTAACTTTTTCССТCCTCAG-3' & \multirow{2}{*}{171} \\
\hline Exon $1-4 \mathrm{R}$ & 5'-GAGAAAACATCACAAACTGG-3' & \\
\hline Exon $2 \mathrm{~F}$ & 5'-AGATGGAGTTTCACTCTTGTTGC-3' & \multirow{2}{*}{185} \\
\hline Exon $2 \mathrm{R}$ & 5'-CATGGTGAAACTCCGTCTCTACT-3' & \\
\hline Exon 3-1F & 5'-TTTGCTAGTTATTAAAGGGATG-3' & \multirow{2}{*}{200} \\
\hline Exon 3-1R & 5'-GCTATAGCATTCAGTTTTGTCT-3' & \\
\hline Exon 3-2F & 5'-TTTGGTCAGCACTAGAACAG-3' & \multirow{2}{*}{197} \\
\hline Exon $3-2 R$ & 5'-AATGAAACAAGAAAAATGGC-3' & \\
\hline
\end{tabular}


amplified with 7 sets of primers covering the entire coding region (exon 1 to 3 ) of the KCNRG gene. Table 1 shows the primer sequences. The numbering of the DNA of KCNRG was carried out with respect to the ATG start codon according to the genomic sequence of the Genbank accession no. NM_024524. All cases were screened for the presence of an aberrant band in the tumor DNA by SSCP analysis of each exon and compared with the normal DNA. After detecting a mutant allele on the SSCP gel, fresh DNA from the case showing a mobility shift was amplified for 35 cycles using the same primer set. The sequencing of the PCR products was carried out using a cyclic sequencing kit (Perkin-Elmer, Foster City, CA) according to the manufacturer's recommendation.

\section{Loss of heterozygosity (LOH) analysis}

The HCCs and corresponding non-cancerous liver DNA was amplified using a thermal cycler (MJ Research Institute, Watertown, MA) with the microsatellite markers, D13S272 and D13S273, which are located $\sim 0.26 \mathrm{Mb}$ and $\sim 0.11 \mathrm{Mb}$ from the KCNRG locus, respectively. Each $P C R$ reaction was carried out under the same conditions as those previously described (Vaish, et al., 2004). The complete absence of one allele in the tumor DNA of the informative cases, as defined by direct visualization, was considered to be a LOH.

\section{Expression patterns of the KCNRG gene by Reverse Transcription-Polymerase Chain Reaction (RT-PCR)}

Expression analysis was carried out in 68 cases with a high RNA quality. Three $\mu \mathrm{g}$ of the total RNA was reverse transcribed for single-strand CDNA using the oligo $(\mathrm{dT})_{15}$ primer and reverse-transcriptase (Roche Molecular Systems, Inc., Branchburg, NJ). Each single-strand was used as a template for subsequent PCR. One set of primers was designed using the OLIGO software program (version 5.0; National Bioscience Inc., Plymouth, MN) according to the cDNA sequence of the gene (GenBank accession no. NM_173605). RT-PCR was performed using the primers in exon 1 (5'-CTTCCACTGCCTCCACAAAGA-3') and exon 3 (5'-CTGACCAAATGAAAGCCTTCCTT-3'). The tumor and corresponding normal cDNA from each case was amplified using a thermal cycler (MJ Research Institute, Watertown, MA) with the primers. PCR was carried out in a volume of 20 $\mu$ for 4 min at $94^{\circ} \mathrm{C}$ for initial denaturing, followed by 35 cycles of $94^{\circ} \mathrm{C}$ for $30 \mathrm{~s}, 62^{\circ} \mathrm{C}$ for $30 \mathrm{~s}$, and $72^{\circ} \mathrm{C}$ for $30 \mathrm{~s}$. A final extension was continued for $10 \mathrm{~min}$. The amplified products were visualized on $1 \%$ agarose gel with ethidium bromide. GAPDH mRNA was also amplified using the same PCR reactions as the internal control using the following primers; 5'-CGGAGTCAACGGATTTGGTCGTAT-3' and 5'-AGCCTTCTCCATGGTGGTGA AGAC-3'.

\section{Western Blot analysis}

The hepatoma cells, Hep3B, were maintained in RPMI-1640 (Bio Whittaker, Walkersville, MD) supplemented with $10 \%$ FBS, $1 \mathrm{mM}$ L-glutamine and antibiotics and cultured at $37^{\circ} \mathrm{C}$ in $5 \% \mathrm{CO}_{2}$. After 24 $\mathrm{h}$, the Hep3B cells were plated in 6 -well plates and transfected with the wild- or mutant-type KCNRG gene that had been construct using the FuGENE6 transfection reagent (Roche Applied secience, Indianapolis, IN), according to the manufacture's recommendation. The mutant-type KCNRG construct was produced using a Quick Change Site- Directed Mutagenesis kit (Stratagene, La Jolla, CA). The cells were harvested 1 day later and lysed in an ice-cold Nonidet P-40 lysis buffer supplemented with a $1 \mathrm{X}$ protease inhibitor mix (Roche Molecular Biochemicals, Mannheim, Germany). The cell lysates were separated on $10 \%$ polyacrylamide gel and blotted onto a hybond PVDF transfer membrane (Amersham Pharmacia Biotech, Piscataway, NJ), which had been subsequently probed with the anti-GFP antibody (Zymed Laboratories, South Sanfrancisco, $\mathrm{CA}$ ), and then incubated with anti-mice IgG conjugated with horseradish peroxidase (HRP). The protein bands were detected using enhanced chemiluminescence Western blotting detection reagents (Amersham Pharmacia Biotech, Piscataway, NJ).

\section{Anti-proliferative effect of KCNRG}

The in vivo anti-proliferative effect of $K C N R G$ was confirmed using a [3-(4,5-dimethylthiazol-2-yl)-5-(3carboxymethoxyphenyl)-2-(4-sulfophenyl)-2H-tetraz olium; MTS] cell proliferation assay (Promega, Madison, $\mathrm{WI})$. Cell proliferation was determined using a CellTiter96 ${ }^{\circledR}$ Aqueous One Solution Cell Proliferation kit (Promega, Madison, WI), according to the manufacture's instructions. Briefly, after transfection and incubation for 1 to 5 days, $20 \mu$ of a MTS and PES (phenaxine ethosulfate) mixture was added to each well and incubated for $4 \mathrm{~h}$. The wells were then measured using a 96 well plate reader at $490 \mathrm{~nm}$. Each experiment was repeated 4 times. The results show the $O D$ ratio at the indicated time points and each data point represents the mean \pm SD. Statistical analysis was carried out using One-way ANNOVA \& Duncan's multiple range tests. $P$-value of $<0.05$ was considered significant. 
A

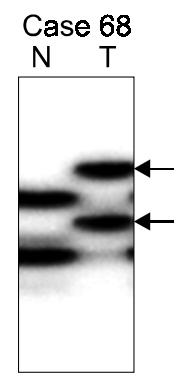

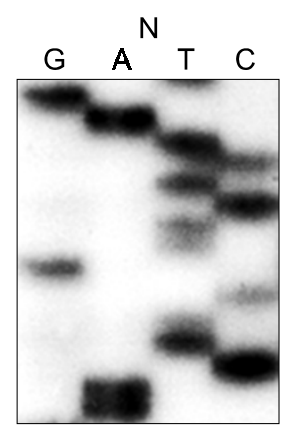

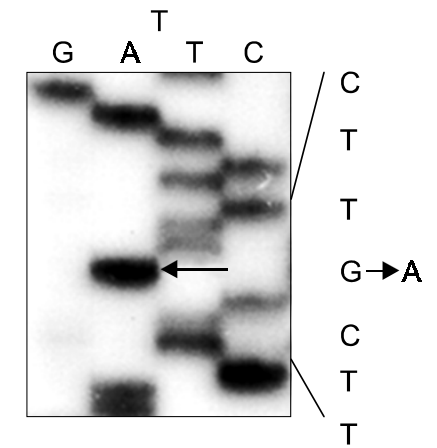

B

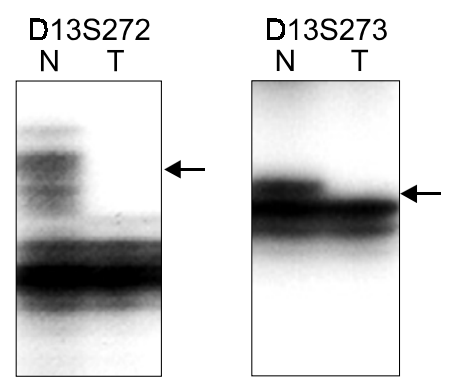

Figure 1. Representative results showing SSCP-sequencing and LOH analysis of the KCNRG gene. (A) SSCP demonstrating only aberrant bands (arrows) and sequencing data showing a missense mutation, a C to T transition at codon 92 of KCNRG gene, in case 68. (B) LOH (arrow) at microsatellite marker D13S272 and D13S273. N, normal DNA; T, tumor DNA.

\section{Electrophysiological recording}

For the electrophysiological experiment, KCNRG expression in 10 liver tumor cell lines, including PLC/PRF5, Hep3B, SNU-182, SNU-354, SNU-368, SNU-387, SNU-398, SNU-423, SNU-449, SNU-475 and immortalized normal liver cell line THLE-3, was analyzed by RT-PCR. Surprisingly, all the cell lines expressed the KCNRG transcript (data not shown). Therefore, LNCap cells, which showed dramatic inhibition of $\mathrm{K}^{+}$fluxes of KCNRG, were used (Ivanov et al., 2003). The LNCaP cells transfected with either the wild- or mutant-type of the KCNRG gene were grown on a coverslip at a density of $2.0 \times 10^{5} / \mathrm{ml}$ in the medium for 2 days after transfection. The whole-cell patch clamp method was used to measure the activity of the voltage-dependent $\mathrm{K}^{+}$channels, as previously described (Ivanov et al., 2003). The cells on a coverslip were transferred to the recording chamber and superfused continuously with the extracellular solution $(1.5-2 \mathrm{ml} / \mathrm{min})$ containing $125 \mathrm{mM} \mathrm{NaCl}, 2.5 \mathrm{mM} \mathrm{KCl}, 2 \mathrm{mM} \mathrm{CaCl}_{2}, 1$ $\mathrm{mM} \mathrm{MgSO}_{4}, 1.25 \mathrm{mM} \mathrm{KH}_{2} \mathrm{PO}_{4}, 25 \mathrm{mM} \mathrm{NaHCO}_{3}$, and $10 \mathrm{mM}$ D-glucose, bubbled with $95 \% \mathrm{O}_{2}$ and $5 \%$ $\mathrm{CO}_{2}(290-295 \mathrm{mOsm})$. All recordings were carried out at $32-33^{\circ} \mathrm{C}$. The patch electrodes $(2-5 \mathrm{M} \Omega$ ) were filled with a pipette solution containing $80 \mathrm{mM}$ potassium gluconate, $10 \mathrm{mM} \mathrm{KCl}, 3 \mathrm{mM}$ MgATP, 10 $\mathrm{mM}$ phosphocreatine, $0.3 \mathrm{mM}$ GTP, $10 \mathrm{mM}$ BAPTA [1,2-bis(2-aminophenoxy)ethane- $N, N, N^{\prime},{ }^{*} N^{\prime}$-tetraace tic acid], $1 \mathrm{mM} \mathrm{CaCl}, 10 \mathrm{HEPES}, 50 \mathrm{U} / \mathrm{ml}$ creatine phosphokinase ( $\mathrm{pH} 7.25$ with $\mathrm{KOH})$. The measured osmolarity of the pipette solution was $286 \mathrm{mOsm}$. In order to prevent possible contamination of the calcium-dependent $\mathrm{K}^{+}$channels (Skryma et al., 1999; Kim et al., 2001; Ivanov et al., 2003), the free calcium concentration of the pipette solution was buffered with $10 \mathrm{mM}$ BAPTA to $0.04 \mu \mathrm{M}$, calculated using 'WinMAXC' software (from Chris Patton,
Hopkins Marine Station, Stanford University, CA). The cells showing a bright green fluorescence on the fluorescence microscope were chosen. After obtaining the whole-cell mode, the $\mathrm{K}^{+}$current was evoked with a $10 \mathrm{mV}$ step increase in the command potential for $500 \mathrm{msec}$ from a holding potential of -70 $\mathrm{mV}$. The current density was obtained from the current amplitude at $40 \mathrm{mV}$ divided by the membrane capacitance (Rhie et al., 2001). The results are expressed as the mean \pm S.E. The data was compared using Analysis of variance (ANOVA) on the Ranks. $P$-value $<0.05$ was considered significant.

\section{Results}

\section{Mutations of the KCNRG gene in HCCs}

PCR-SSCP and sequencing analysis was used to search for potential mutations in all 3 exons of the KCNRG gene in 77 HCCs. Direct sequencing of an aberrantly migrating band on SSCP gel led to the identification of a mutation in $1(1.3 \%)$ of the HCCs examined. The mutation was a missense mutation, CGT $\rightarrow$ CAT at codon 92 in exon 1 encoding the KCNRG T1 domain, which is a codon from 6 to 101 (Figure 1A). This mutation caused a Arg to His substitution, which is a conservative mutation. The corresponding normal sample showed no evidence of mutations by repeated SSCP, indicating that the mutation was a somatic mutation. The mutation was found in a patient with a HBV-positive, cirrhotic background, and clinical stage 3 . The tumor showed an infiltrative growth pattern, histology grade 3 and an intrahepatic metastasis. The experiments were repeated three times, including PCR and SSCPsequencing, to confirm the results and the data were found to be consistent. 


\section{LOH analysis}

The allelic loss was also analyzed using two microsatellite markers, D13S272 and D13S273 in order to confirm that the KCNRG gene is one of the candidate tumor suppressor genes associated with the development of human HCCs. Patients who were heterozygous for the microsatellite markers were

Table 2. Genetic alteration of the KCNRG in HCCs.

\begin{tabular}{|c|c|c|c|}
\hline & Mutation & $\mathrm{LOH}$ & $P$ \\
\hline Background & & & .9615 \\
\hline Cirrhosis & 1 & $13 / 44$ & \\
\hline Fatty change & & $0 / 1$ & \\
\hline $\mathrm{CAH}$ & & $2 / 7$ & \\
\hline $\mathrm{CPH}$ & & $0 / 2$ & \\
\hline NON & & $2 / 10$ & \\
\hline Hepatitis virus & & & .2231 \\
\hline B & 1 & $17 / 56$ & \\
\hline C & & $0 / 1$ & \\
\hline N-S & & $0 / 7$ & \\
\hline Grade & & & .0078 \\
\hline I & 1 & $0 / 7$ & \\
\hline II & & $13 / 51$ & \\
\hline III & & $4 / 6$ & \\
\hline Portal vein invasion & & & .0522 \\
\hline+ & 1 & $4 / 7$ & \\
\hline- & & $13 / 57$ & \\
\hline Intrahepatic metastasis & & & .0247 \\
\hline+ & 1 & $10 / 50$ & \\
\hline- & & $7 / 14$ & \\
\hline Stage & & & .0071 \\
\hline I & 1 & $0 / 6$ & \\
\hline II & & $5 / 28$ & \\
\hline III & & $8 / 23$ & \\
\hline IV & & $4 / 7$ & \\
\hline Total & 1 & $17 / 64$ & \\
\hline
\end{tabular}

$\mathrm{LOH}$, loss of heterozygosity (LOH/informative cases); $\mathrm{CAH}$, chronic active hepatitis; $\mathrm{CPH}$, chronic persistent hepatitis; N-S, non specific change. considered to be informative. Sixty-four (83.1\%) out of $77 \mathrm{HCCs}$ were informative at these markers with $17(26.5 \%)$ of those showed an allelic loss at one or both markers. Interestingly, all the HCCs with an allelic loss were HBV-positive. Histologically, an allelic loss was found in $13(25.5 \%)$ of the 51 grade II informative cases and in $4(66.7 \%)$ of the 6 grade III informative cases. In addition, a $\mathrm{LOH}$ was detected in $5(17.9 \%)$ of the 28 stage II informative cases, $8(34.8 \%)$ of the 23 stage III cases, and 4 $(57.1 \%)$ of the 7 stage IV cases. There was a significant correlation between an allelic loss and the histology grades (Bartholomew test, $P=0.0078$ ) and stage (Bartholomew test, $P \leq 0.0071$ ). Furthermore, the number of allelic losses was higher in those cases with an intrahepatic metastasis than in the cases without a metastasis (Chi-Square test, $P=$ 0.0247 ) (Table 2). Figure $1 \mathrm{~b}$ shows the autoradiograms displaying a $\mathrm{LOH}$. Interestingly, the HCC case with a KCNRG mutation showed a $\mathrm{LOH}$ at D13S272 and only aberrant bands of the mutant allele on the SSCP gel, suggesting a hemizygous mutation or a mutation in one allele and loss of the remaining allele (Figure 1).

\section{Expression patterns of the KCNRG gene by RT-PCR}

The expression of the KCNRG gene in $68 \mathrm{HCCs}$ with a high RNA quality was analyzed. Two amplified fragments, 194 bp (variant 1) and 289 bp (variant 2) of cDNA, were demonstrated by RT-PCR analysis (Figure 2). Six of the 68 corresponding non-cancerous tissues expressed only KCNRG transcript variant 1,35 cases showed variant 2 , and 27 cases revealed both variants 1 and 2 . Surprisingly, functional analysis showed there was no significant difference in the potassium regulation activity between variants 1 and 2 (data not shown). Interestingly, $22(32.4 \%)$ tumor tissues from the 68 cases showing expression in the corresponding non-cancerous tissue cells demonstrated a loss of expression of the KCNRG gene (Figure 2). Of the 46 cases showing expression in the $\mathrm{HCC}$, transcript variants 1 and 2 were found in 5 and 27 tumor tissues, respectively, and 14 tumor tissues expressed both variants. In addition, some of the tissues showed different transcript expression in the tumor and

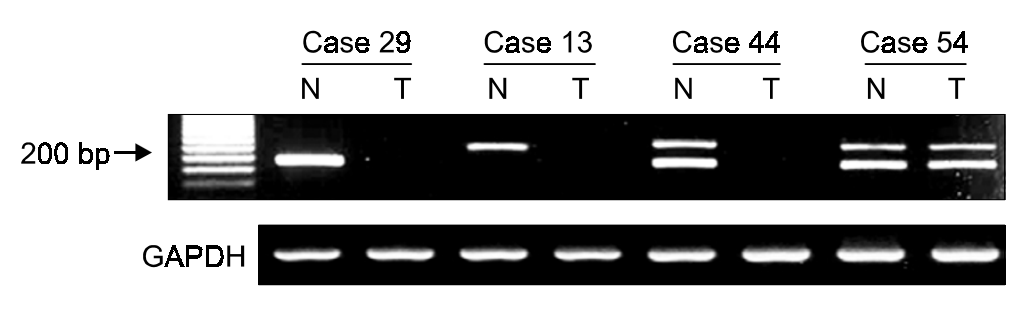

Figure 2. Expression analysis of the $K C N R G$ gene in HCCs. The tumor tissues from case No. 29, 13, and 44 showed a loss of expression. N, normal tissue; T, tumor tissue. 
corresponding normal liver tissue. For example, three cases with expression of variant 1 in the corresponding normal liver tissue expressed only variant 2 in the tumor tissue. A loss of KCNRG expression was detected in $2(11.8 \%)$ of the 17 cases showing an allelic loss, and two (9.1\%) of the 22 cases with a loss of expression showed an allelic loss at the KCNRG locus.

\section{Anti-proliferative effect of KCNRG}

The effect of KCNRG on tumor cell proliferation was examined in Hep3B human hepatoma cells using a MTS proliferation assay. As shown Figure 3B, significant inhibition of Hep3B cell proliferation was observed in the cells transfected with the wild-type $K C N R G$ gene. Interestingly, the growth rate of the mutant KCNRG overexpressing Hep3B cells was considerably lower than that of the cells transfected with the vector only, and was significantly higher than that of the wild KCNRG transfected cells. A significant difference in cell proliferation between the wild- and mutant-type KCNRG was observed 3, 4 and 5 days after transfection (One-way ANNOVA \& Duncan's multiple range tests, $P<0.05$ ).

\section{Effect of overexpression of KCNRG on voltage-dependent potassium current}

The voltage-dependent $\mathrm{K}^{+}$channel activity was measured to determine the effect of a mutation of $K C N R G$, as described previously (Ivanov et al.,
2003). The LNCaP cells showed a large noninactivating voltage-dependent $\mathrm{K}^{+}$current with an incremental membrane voltage step (Figure 4A). Although the $\mathrm{K}^{+}$current amplitude was variable among the individual cells, the $\mathrm{K}^{+}$current density of the cells overexpressing the wild-type KCNRG was lower than that of the control cells $(20.2 \pm \mathrm{pA} / \mathrm{pF}, n=$ 16 vs. $65.0 \pm 17.85 \mathrm{pA} / \mathrm{pF}, n=11 ; P<0.05)$, suggesting that KCNRG negatively regulates the voltagedependent $\mathrm{K}^{+}$channel activity in LNCaP cells. Although there was no statistical difference in the $\mathrm{K}^{+}$ current density between the wild- and mutant-type $K C N R G$, there was a partial loss of the negative regulatory role of the voltage-dependent $\mathrm{K}^{+}$channel in the mutant-type KCNRG $(45.4 \pm 11.1 \mathrm{pA} / \mathrm{pF}, n=$ 15). The cell capacitance was similar in all the groups (data not shown).

\section{Discussion}

Selective blockers of the $\mathrm{K}^{+}$channels suppress the lymphocyte and colon cancer cell lines, and VGPCs have been implicated in the cellular proliferation of normal and transformed cells (Yao et al., 1999; Abdul and Hoosein, 2001). Melanoma cells express a variety of ion-channel types, and $\mathrm{K}^{+}$channelblockers have been reported to inhibit melanoma and breast cancer growth (Strobl et al., 1995; Allen et al., 1997). In addition, the overexpression of KCNK9 encoding a potassium channel promotes

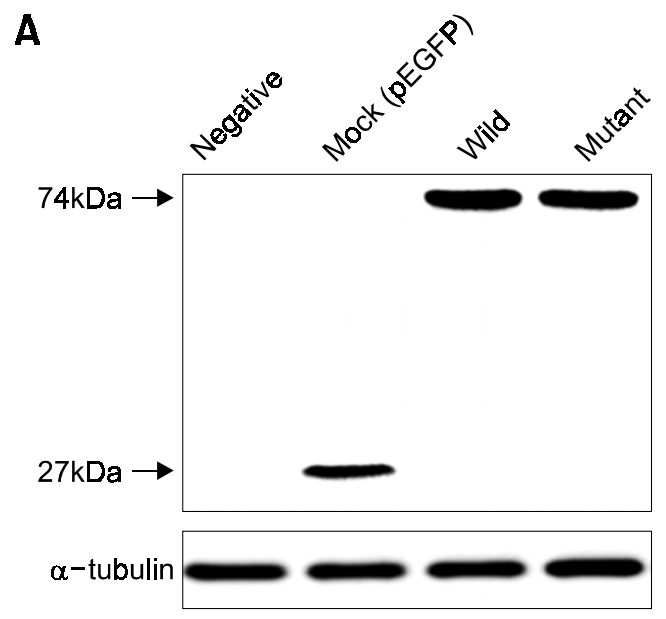

B

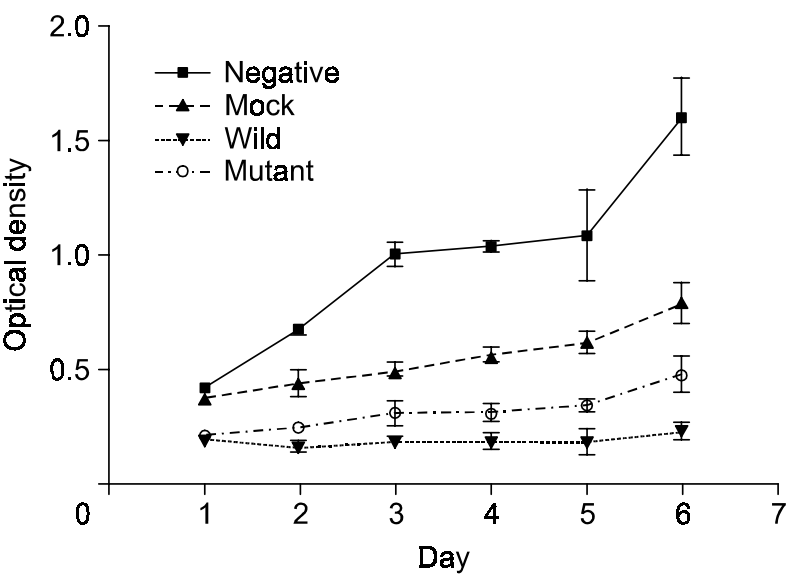

Figure 3. Expression and effect of $K C N R G$ on cell proliferation in vitro. (A) Expression of $K C N R G$ in the Hep3B cells transfected with pEGFP, wildor mutant-type KCNRG-pEGFP was assayed by Western blot analysis. The membrane was immunoblotted with the anti-GFP antibody and $\alpha$-tubulin was used as the loading control. (B) The effect of the wild- or mutant-KCNRG on Hep3B cell proliferation was examined by a MTS proliferation assay. Transfection of the wild-type KCNRG caused the dramatic inhibition of Hep3B cells, but mutant KCNRG was unable to reduce the level of cell proliferation. The data is shown as a mean \pm SD of 4 individual experiments. Scale bar $=$ SD. 
A
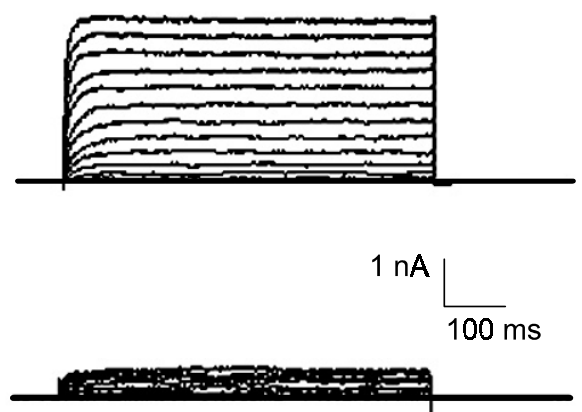

B

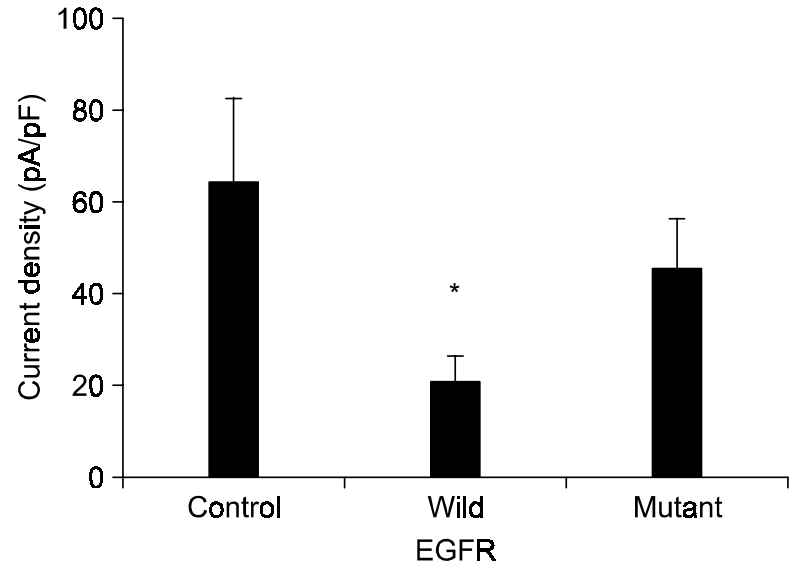

Figure 4. Effect of KCNRG overexpression on the voltage-dependent $\mathrm{K}^{+}$channels in LNCaP cells. (A) Representative current traces of the control (left panel) and wild-type of $K C N R G$ (right panel). The $\mathrm{K}^{+}$current was evoked with a $10 \mathrm{mV}$ step increment of the command potential from a $-70 \mathrm{mV}$ holding potential. (B) Summary of the $\mathrm{K}^{+}$current density in the control $(n=11)$ and cells transfected with the wild- $(n=16)$ and mutant-type $(n=15) K C N R G$. $\mathrm{K}^{+}$current amplitude was measured at a command potential of $40 \mathrm{mV}$. The data represents mean \pm S.E. $\left({ }^{*} P<0.05\right.$, vs. control).

tumor formation and confers resistance to both hypoxia and serum deprivation (Mu et al., 2003). Recently, Ivanov et al. identified 2 splice variants of the KCNRG gene encoding the potassium channel regulating protein on chromosome 13q14.3 (Ivanov et al., 2003). The deduced amino acid proteins of the 2 variants differed only in their C-terminal sequences. Both shared sequence similarity with the cytoplasmic tetramerization domain of the VGPCs and contained a putative BTB/POZ domain (Ivanov et al., 2003). These results strongly suggest that KCNRG acts as a tumor suppressor gene for the development or progression of various types of cancers, including $\mathrm{HCC}$, and that genetic alterations in the $K C N R G$ gene might contribute to the tumorigenesis of HCC.

This study examined the genetic alterations and the expression pattern of the KCNRG gene in a series of 77 HCCs. One missense mutation was found at codon 92 of the KCNRG gene (Figure 1). It is known that KCNRG, which is a regulatory protein, can interfere with the assembly of the $\mathrm{K}^{+}$channel protein (Ivanov et al., 2003). This study investigated the effect of the mutant KCNRG on cell proliferation using a MTS assay and on voltage-dependent potassium channel activity through an electrophysiological study. Interestingly, the level of Hep3B cell proliferation was significantly lower in the wild-type $K C N R G$ transfected cells. However, the growth rate in the Hep3B cells transfected with the mutant $K C N R G$ was significantly higher than that of the wild $K C N R G$ transfected cells (Figure 3 ). The mutation detected in this study might be an inactivating mutation and the endogenous wild-type KCNRG in
Hep3B cells suppressed cell proliferation. The potassium current density in the wild-type KCNRGtransfected cells was significantly lower than that of the control cells, as expected. In addition, the mutant-type KCNRG-transfected cells demonstrated a loss of negative potassium current regulation (Figure 4), indicating that the conservative mutation, $\mathrm{R} 92 \mathrm{H}$, might induce a loss of the KCNRG functions through a structural alteration. Therefore, these results suggest that a structural alteration in the $K C N R G$ gene by a somatic mutation is involved in the development or progression in a subset of HCC. Deletions of chromosome $13 q$ have been reported in many types of human malignancies including HCC, which suggests the presence of a tumor suppressor gene in this region (Niketeghad et al., 2001; Crawley et al., 2002; Kusano et al., 2002; Wong et al., 2002). In this study, allelic deletions in the HCCs were also analyzed using the microsatellite markers, D13S272 and D13S273. A LOH was found in $17(26.5 \%)$ out of 64 informative cases of HCCs, and all of them were HBV-positive cases. An infection with either the $\mathrm{HBV}$ or $\mathrm{HCV}$, the ingestion of aflatoxin B1-contaminated food, and heavy alcohol consumption are important risk factors for human HCC. Despite of the fact that epidemiologic evidence indicates that the $\mathrm{HBV}$ is a major risk factor for the development of HCC (Robbins et al., 1994), the precise mechanisms of this association are unknown. The site of the cellular DNA at which the HBV integrates frequently undergoes rearrangement, resulting in a translocation, and deletion (Ogata et al.,1990; Hino et al., 1996; Nakamura et al., 1998; Okabe et al., 2000). Furthermore, an allelic loss at $13 q$ is significantly 
associated with an advanced tumor stage and a poor prognosis (Zondervan et al., 2000; Kusano et al., 2002; Wong et al., 2002). Therefore, it is possible that an allelic loss of KCNRG could be an additional mechanism for the progression of HCC. Interestingly, there was a significant correlation between the allelic loss and histological grades and stage. In addition, the frequency of allelic losses was higher in the cases with an intrahepatic metastasis than in those without a metastasis (Table 2). Although more detailed studies will be needed to clarify the causative mechanism of the KCNRG gene, these results suggest that an allelic deletion of the KCNRG gene might contribute to the aggressiveness of HCCs.

In this study, the wild-type KCNRG significantly suppressed cell growth in Hep3B cells (Figure 3) and $22 \mathrm{HCC}$ tissues did not express the KCNRG transcript (Figure 2). However, only one somatic missense mutation and a lower frequency $(26.5 \%)$ of allelic losses were found. Therefore, molecular mechanisms other than a structural alteration might be responsible for the KCNRG gene silencing. Surprisingly, there were no GC-rich sequence in the KCNRG gene (GenBank accession no. NM_173605). These GC-rich sequences are called $\mathrm{CpG}$ islands, which are often located within the 5' regulatory nontranscribed regions of genes. It is possible that unknown transcription factors that bind to the enhancer or silencer of the gene might play a role in the different expression of the gene. These results are expected to broaden the understanding of the pathogenesis of human HCC. However, more study on the mechanism of KCNRG silencing will be needed to verify this initial observation.

\section{Acknowledgement}

This work was supported by the Korea Research Foundation Grant (KRF-2004-015-E00086).

\section{References}

Abdul M, Hoosein N. Voltage-gated potassium ion channels in colon cancer. Oncol Rep 2001;9:961-4

Allen DH, Lepple-Wienhues A, Cahalan MD. Ion channel phenotype of melanoma cell lines. J Membrane Biol 1997;155: 27-34

Chen CJ, Yu MW, Liaw YF. Epidemiological characteristics and risk factors of hepatocellular carcinoma. J Gastroenterol Hepatol 1977;12:S294-S308

Crawley JJ, Furge KA. Identification of frequent cytogenetic aberrations in hepatocellular carcinoma using gene-expression microarray data. Genome Biol 2002;3:research0075 Hino O, Shows TB, Rogler CE. Hepatitis B virus integration site in hepatocellular carcinoma at chromosome 17:18 translocation. Proc Natl Acad Sci 1996;83:8338-42

Ivanov DV, Tyazhelova TV, Lemonnier L, Kononenko N, Pestove AA, Nihitin EA, Prevarskaya N, Skryma R, Panchin YV, Yankovsky NK, Baranova AV. A new human gene KCNRG encoding potassium channel regulating protein is a cancer suppressor gene candidate located in 13q14.3. FEBS Letters 2003;539:156-60

Kim JH, Hong EK, Choi HS, Oh SJ, Kim KM, Uhm DY, Kim SJ. $\mathrm{K}^{+}$channel currents in rat ventral prostate epithelial cells. Prostate 2001;51:201-10

Kumar V, Cotran RS, Robbins SL. Neoplasia. In Robbins Basic Pathology. 2003, 165-210, W. B. Saunders, Philadelphia

Kusano N, Okita K, Shirahashi H, Harada T, Shiraishi K, Oga A, Kawauchi S, Furuya T, Sasaki K. Chromosomal imbalances detected by comparative genomic hybridization are associated with outcome of patients with hepatocellular carcinoma. Cancer 2002;94:746-51

Mu D, Chen L, Zhang X, Lee LH, Koch CM, Yen C, Tong JJ, Spiegel L, Nguyen KC, Servoss A, Peng Y, Pei L, Marks JR, Lowe S, Hoey T, Jan LY, McCombie R, Wigler MH, Powers S. Genomic amplification and oncogenic properties of the KCNK9 potassium channel gene. Cancer Cell 2003;3:297302

Nakamura T, Tokino T, Nagaya T, Matsubara K. Microdeletion associated with the integration process of hepatitis $B$ virus DNA. Nucleic Acids Res 1998;16:4865-73

Niketeghad F, Decker HJ, Caselmann WH, Lund P, Geissler $F$, Dienes HP, Schirmacher P. Frequent genomic imbalances suggest commonly altered tumour genes in human hepatocarcinogenesis. Br J Cancer 2001;85:697-704

Ogata N, Tokino T, Kamimura T, Asakura H. A comparison of the molecular structure of integrated hepatitis $B$ virus genomes in hepatocellular carcinoma cells and hepatocytes derived from the same patient. Hepatology 1990;11:1017-23

Okabe H, Ikai I, Matsuo K, Satoh S, Momoi H, Kamikawa T, Katsura N, Nishitai R, Takeyama O, Fukumoto M, Yamaoka Y. Comprehensive allelotype study of hepatocellular carcinoma: potential differences in pathways to hepatocellular carcinoma between hepatitis B virus-positive and -negative tumors. Hepatology 2000;31:1073-9

Park WS, Cho YG, Kim CJ, Song JW, Lee YS, Kim SY, Nam SW, Lee SH, Yoo NJ, Lee JY. Hypermethylation of the RUNX3 gene in hepatocellular carcinoma. Exp Mol Med 2005;37: 276-81

Rhie DJ, Kim MJ, Choi WS, Lee KH, Sung JH, Min DS, Yoon SH, Hahn SJ, Kim MS, Jo YH. Effect of somatostatin on cholecystokinin-induced amylase release in rat pancreatic acini. Pancreas 2001;23:102-8

Robbins WS. Molecular events in the pathogenesis of hepadnavirus associated hepatocellular carcinoma. Ann Rev Med 1994;45:297-323

Sakamoto M, Hirohashi S, Shimosato Y. Early stages of multistep hepatocarcinogenesis: adenomatous hyperplasia and early hepatocellular carcinoma. Hum Pathol 1991;22:172-8 
Shin HR, Jung KW, Won YJ, Park JG. KCCR-affiliated Hospitals. 2002 Annual report of the Korea central cancer registry: Based on registered data from 139 hospitals. Cancer Research and Treatment 2004;36:103-14

Skryma R, Van Coppenolle F, Dufy-Barbe L, Dufy B, Prevarskaya $\mathrm{N}$. Characterization of $\mathrm{Ca}(2+)$-inhibited potassium channels in the LNCaP human prostate cancer cell line. Receptors Channels 1999;6:241-53

Strobl JS, Wonderlin WF, Flynn DC. Mitogenic signal transduction in human breast cancer cells. Gen Pharmacol 1995;26:1643-9

Vaish M, Mishra A, Kaushal M, Mishra SK, Mittal B. Microsatellite instability and its correlation with clinicopathological features in a series of thyroid tumors prevalent in iodine deficient areas. Exp Mol Med 2004;36:122-9

Wonderline WF, Woodfork KA, Stroble JS. Changes in membrane potential during the progression of MCF-7 human mammary tumor cells through the cell cycle. J Cell Physiol 1995; $165: 177-85$
Wonderlin WF, Strobl JS. Potassium channels, proliferation and G1 progression. J Membrane Biol 1996;154:91-107

Wong CM, Lee JM, Lau TC, Fan ST, Ng IO. Clinicopathological significance of loss of heterozygosity on chromosome $13 q$ in hepatocellular carcinoma. Clin Cancer Res 2002;8:2266-72

Woodfork KA, Wonderlin WF, Peterson VA, Strobl JS. Inhibition of ATP-sensitive potassium channels causes reversible cell-cycle arrest of human breast cancer cells in tissue culture. J Cell Physiol 1995;162:163-71

Yao X, Kwan HY. Activity of voltage-gated $\mathrm{K}^{+}$channels is associated with cell proliferation and $\mathrm{Ca}^{2+}$ influx in carcinoma cells of colon cancer. Life Sci 1999;65:55-62

Zondervan PE, Wink J, Alers JC, ljzermans JN, Schalm SW, de Man RA, van Dekken H. Molecular cytogenetic evaluation of virus-associated and non-viral hepatocellular carcinoma: analysis of 26 carcinomas and 12 concurrent dysplasias. J Pathol 2000;192:207-15 